\title{
Application of Geospatial Methods in Evaluating Environmental Interventions and Related Socioeconomic Benefits
}

\author{
Anupam Anand and Geeta Batra
}

\section{Abstract}

Environmental interventions underpin the Sustainable Development Goals (SDGs) and the Rio Conventions. The SDGs are integrated and embody all three aspects of sustainable development-environmental, social, and economic - to capture the interlinkages among the three areas. The Rio Conventionson biodiversity, climate change, and desertification, also intrinsically linked-operate in the same ecosystems and address interdependent issues, and represent a way of contributing to the SDGs. Assessing the results of environmental interventions and the related socioeconomic benefits is challenging due to their complexity, interlinkages, and often limited data. The COVID-19 crisis has also necessitated creativity to ensure that evaluation's critical role continues during the crisis. Satellite and other geospatial information, combined with existing survey data, leverage open-source and readily available data to determine the impact of projects. Working with geospatial data helps maintain flexibility and can fill data gaps without designing new and often expensive data tools for every unique evaluation. Using data on interventions

A. Anand $(\bowtie) \cdot$ G. Batra

Global Environment Facility Independent Evaluation

Office, Washington, DC, USA

e-mail: aanand2@thegef.org; gbatra@thegef.org implemented by the Global Environment Facility in biodiversity, land degradation, and climate change, we present the application of geospatial approaches to evaluate the relevance, efficiency, and effectiveness of interventions in terms of their environmental outcomes and observable socioeconomic and health co-benefits.

\section{Introduction}

Environmental interventions are important mechanisms for delivering the objectives laid out in the Sustainable Development Goals (SDGs) and the United Nations Rio Conventions. The SDGs are integrated and embody all three aspects of sustainable development-environmental, social, and economic-with the intention of capturing the interlinkages among the three areas (United Nations Environment Programme [UNEP], 2013). The three Rio Conventions - on biodiversity, climate change, and desertification, also intrinsically linked-operate in the same ecosystems and address interdependent issues, and represent a way of contributing to the SDGs. The various activities related to sustainable development are linked through feedback mechanisms, resulting in both benefits and tradeoffs. This is where a systems approach that recognizes the dynamic, interdependent complexity of real- 
world contexts across different scales, and recognizes dynamic shifts over time, is helpful in addressing environmental issues (Kass, 2019).

The Global Environment Facility (GEF) was set up in 1992 as a financial mechanism for the Rio Conventions. The GEF supports the implementation of projects in five focal areas-biodiversity, climate change, land degradation, international waters, and chemicals and wastethrough 18 implementing agencies. Since 2010, the GEF has moved toward integrated programming that seeks to bring about changes in the multiple domains necessary to achieve the desired long-term transformation. These programs consider causes across the environment and different realms of human activity, generate benefits in two or more GEF focal areas, and generate social and economic benefits. This recent emphasis on multifocal and integrated programming presents its own sets of challenges, primarily those of evaluating the results and measuring other related benefits.

Drawing on GEF projects and programs in biodiversity, land degradation, and climate change, this chapter presents the application of geospatial approaches to evaluate the relevance, results, and sustainability of GEF interventions in terms of their environmental outcomes and their socioeconomic and health co-benefits. The first section of the chapter includes an introduction to geospatial data and analysis, the trends in its use, and the reasons behind the increase in the use of these approaches. The next section illustrates the usefulness of geospatial data in evaluation using examples of specific applications by the GEF Independent Evaluation Office (IEO). The final section discusses insights from geodata applications in environmental evaluations.

\section{Geospatial Approaches and Methods}

Geospatial data is unique because it contains spatially explicit information. The data can be collected from various sources such as remote sensing platforms, geotagged photographs, and ground sensors, or from survey data sets that include such information. Geospatial methods include the creation, collection, analysis, visualization, and interpretation of geospatial data.

Thus, geospatial data and methods can provide spatially explicit, synoptic, time-series data for various earth system processes, and have been used in the monitoring of environmental processes over the past 40 years (Awange \& Kyalo Kiema, 2013; Melesse et al., 2007; Spitzer, 1986). Its application in environmental evaluations has gained traction in the last 2 decades. Evaluators initially used geographic information systems mainly to visualize and detect change in combination with other evaluation data (Renger et al., 2002). Others in evaluation have recognized the usefulness of spatial data for determining baselines, outputs, and monitoring of results over time (Azzam, 2013; Azzam \& Robinson, 2013). Evaluators have employed quasiexperimental designs (Andam et al., 2008; Buchanan et al. 2016; Ferraro \& Pattanayak, 2006) using geospatial data in impact evaluations of biodiversity and forestry interventions. Geospatial analysis has also been used recently in randomized control trials (Jayachandran et al., 2017).

\section{Drivers of Increased Use}

Recognition of the role of geospatial science by intergovernmental agencies and major environmental and development policy frameworks is growing as countries move toward more evidence-based policy decisions (Lech et al., 2018). The United Nations Convention to Combat Desertification (UNCCD) has recommended using indicators obtained from remote sensing to monitor progress toward reversing and stopping land degradation and desertification (Minelli et al., 2017). The United Nations Framework Convention on Climate Change (UNFCCC) and the Convention on Biological Diversity (CBD) have also endorsed the use of objective indicators, many of which are derived through geospatial methods.

Other factors have influenced the increased use of geospatial data and analysis. First, we have seen an unprecedented flow of spatial data from multiple sources, including satellite data. 
Moderate and coarse resolution data is free, and high-resolution data is becoming less expensive and more widely available. The recent developments in data science have influenced the availability and cost of data. The infrastructure and tools to work with large quantities of geospatial data or big geodata have increased substantially. The availability of application programming interfaces (APIs), cloud-based services, and browser-based development environments have allowed access to geospatial data and analysis without the need for significant computational infrastructure (Lech et al., 2018). Traditional statistical tools are often incapable of dealing with the volume and variety of geospatial datasets, thus paving the way for machine learning and artificial intelligence algorithms in the last 5-7 years.

\section{Use of Geospatial Data and Analysis in Monitoring and Evaluation}

Evaluators often encounter methodological challenges and data issues during the course of evaluations, including lack of baseline data, sampling bias, difficulties in selecting appropriate counterfactuals, and accounting for the impact of multiple scales and contexts on processes and interventions. Geospatial approaches and tools can effectively address these gaps and can be applied to evaluate environmental and socioeconomic outcomes, to measure environmental change. We can also combine them with existing qualitative and quantitative methods and the results of interventions over time, while recognizing and accounting for the complex interrelationships across the various factors.

\section{Application of Geospatial Approaches by the GEF IEO}

The GEF IEO has been one of the earliest adopters of geospatial methods to answer important evaluation questions on the relevance, effectiveness, efficiency, and sustainability of GEF interventions. This section presents examples from GEF IEO evaluations.

\section{Assessing the Relevance of GEF- Supported Interventions to Combat Land Degradation and Desertification}

As the financial mechanism of the UNCCD, the GEF uses land degradation focal area strategies consistent with the UNCCD global priorities, including its focus on combating desertification in Africa, emphasis on drylands and nondrylands, and achieving land degradation neutrality. The GEF is gradually moving toward integrated approaches in this area to deliver global environmental benefits in multiple focal areas while generating local environmental and development benefits. A 2017 land degradation focal area study conducted by the IEO analyzed 618 land degradation projects or multifocal area projects with a land degradation component. The study looked at the relevance and performance of GEF's investments in addressing land degradation.

The IEO used geospatial analysis to assess the relevance of GEF interventions at global, country, and site levels. The analysis involved a feature overlay of the GEF-supported land degradation projects with the areas of land degradation severity. The analysis showed that the GEF implemented interventions to address land degradation in all developing regions of the world (Fig. 1) with Africa appropriately receiving the highest share of land degradation focal area project financing (37\%), followed by Latin America and the Caribbean with 24\% (GEF IEO, 2017). Africa has the largest share of land with extreme degradation in semi-arid areas (United Nations Environmental Programme [UNEP], 2002). Degraded soils are also found in regions undergoing deforestation such as Indonesia and Brazil and areas with high population pressure such as China, Mexico, and India (UNEP, 2002).

The study also noted that India, Mexico, Brazil, Indonesia, and China received the majority of land degradation financing from the GEF and the majority of national projects focused on forest and agricultural lands and rangelands. Overall, the results from this study showed that the GEF was supporting land degradation projects where most needed and relevant (GEF IEO, 2017). 


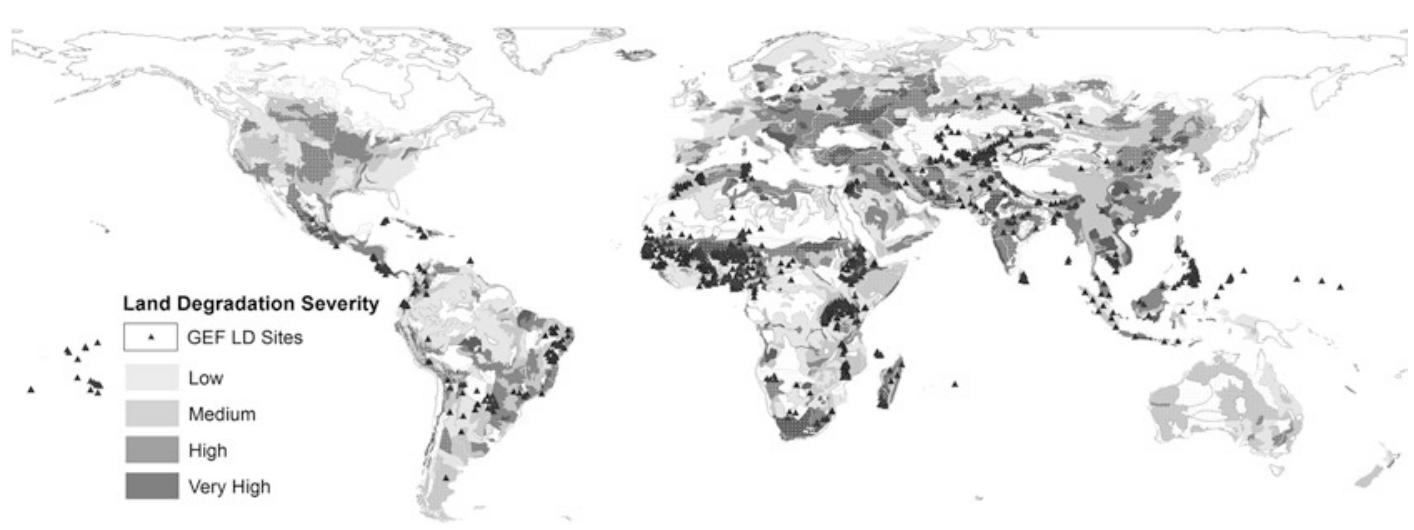

Fig. 1 Land Degradation Levels and GEF Interventions

\section{Assessing Impacts in GEF-Supported Protected Areas}

Protected areas are among the critical strategies for biodiversity conservation (DeFries et al., 2005). Global commitments and targets recognize the importance and role of protected areas in biodiversity conservation, ecosystem services management, poverty reduction, and generation of economic benefits. As the financial mechanism for the United Nations Convention on Biological Diversity (CBD), the GEF applies a strategy consistent with the CBD's strategic plan, reflected in its support to protected areas over the last 26 years. Between 1991 and 2015, the GEF provided $\$ 3.4$ billion in grants to 618 projects involving protected areas, matched by $\$ 12.0$ billion in cofinancing, to help protect almost 2.8 million $\mathrm{km}^{2}$ of the world's non-marine ecosystems (GEF IEO, 2016). These figures exclude the support provided by GEF outside of the protected area systems.

Assessing the effectiveness and impact of GEF-supported protected areas is challenging mainly due to the scale, different timelines, and difficulty in collecting primary data due to the remoteness of protected areas. The IEO addressed these challenges using remote sensing data in the Evaluation of GEF Support to Protected Areas and Protected Area Systems (GEF IEO, 2016). ${ }^{1}$

\footnotetext{
${ }^{1}$ The evaluation was conducted in collaboration with the Independent Evaluation Office of the UNDP.
}

At the global level, the evaluation used observations from satellite data, conducting geospatial analysis for the period 2001-2012 in GEFsupported protected areas and their buffers at 10 and $25 \mathrm{~km}$ to compare the extent of forest loss in these areas. The study examined forest change for 37,000 protected areas in 147 countries using a global dataset derived from satellite data analysis (GEF IEO, 2016).

Results of satellite data analysis of GEFsupported protected areas demonstrated that these protected areas experienced less forest loss than their surrounding $10 \mathrm{~km}$ buffer zones (see Fig. 2). In the 2001-2012 period, GEF-supported protected areas had up to four times less forest cover loss than the overall respective country averages, and at least two times less than protected areas not supported by the GEF in the same biomes and countries.

Using analysis through the biome lens, the evaluation found the greatest loss in protected areas in tropical and subtropical moist broadleaf forests, followed by tropical and subtropical conifers and tropical and subtropical dry broadleaf forest biomes (see Fig. 3). The findings confirmed the global trend of the most extensive forest loss in the tropics, followed by boreal and subtropical forests. The percentage loss of forest cover was highest in temperate conifers and temperate grassland, followed by tropical and subtropical grasslands, savannas, and scrublands; and then tropical and subtropical dry broadleaf forests. These results are consistent with global 


\section{Forest Cover Change Analysis}

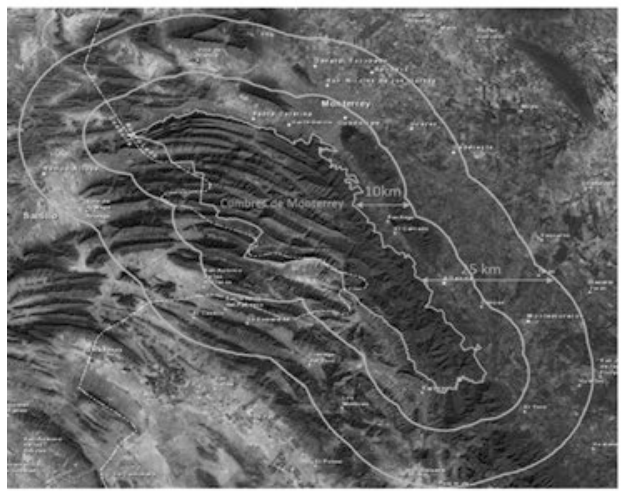

Decadal Forest Cover, Gain and Loss (2000 - 2012)

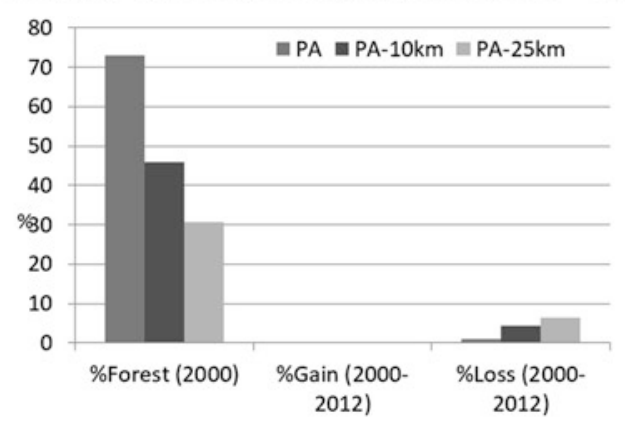

Percent Tree Cover (2000)
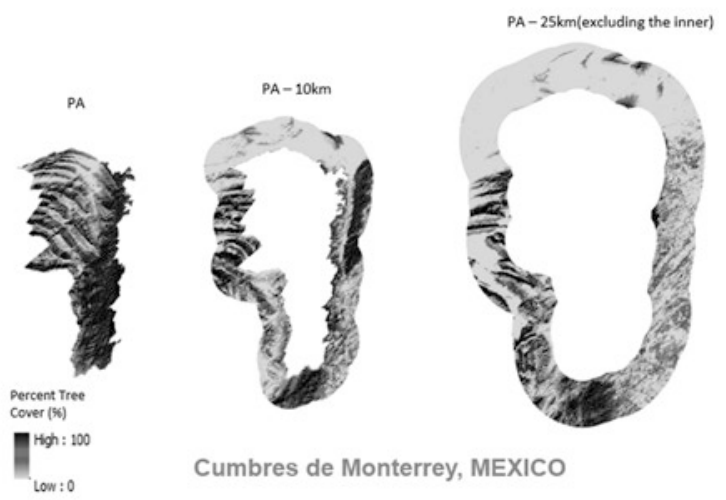

Cumbres de Monterrey, MEXICO

Yearly Percent of Forest Loss (2000 - 2012)

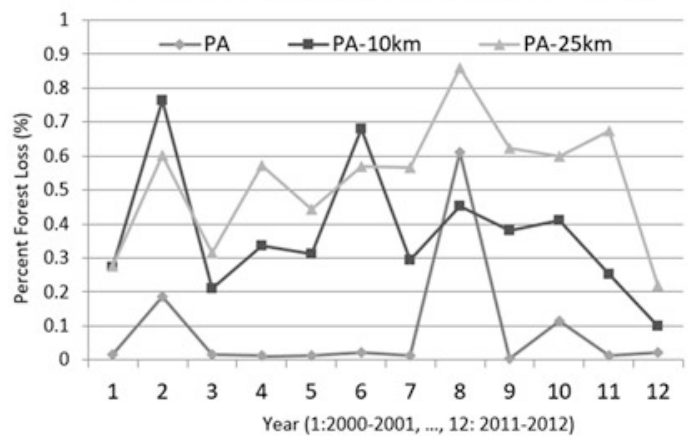

Fig. 2 Forest Loss in Protected Areas vs. Surrounding Areas

trends of tropical and subtropical forests exhibiting the most significant loss, followed by temperate and boreal forests (Hansen et al., 2013). These findings indicate the GEF's relevance to protected areas and affirm that the funding is going to areas experiencing a significant loss in protected forests - an important indicator of ecosystem integrity.

The results also showed that the median percent forest loss in GEF-supported protected areas was $1.2 \%$ percent while averaging $4.1 \%$ in the countries. The highest net percent forest losses were seen in Côte d'Ivoire (14.72\%), South Africa (6.75\%), and Guatemala (5.37\%), and the highest net area forest losses were observed in Nicaragua (2528.76 $\left.\mathrm{km}^{2}\right), \quad$ Honduras $\left(1592.78 \mathrm{~km}^{2}\right)$, and Bolivia $\left(1072.29 \mathrm{~km}^{2}\right){ }^{2}$

${ }^{2}$ Details of the approach, data, methods, and key findings of this evaluation can be found in the original evaluation report (GEF IEO, 2016).

\section{Assessing Socioeconomic Co-Benefits}

Despite widespread interest and extensive research into the socioeconomic impacts of environmental interventions in the past few decades, evidence remains inadequate and inconsistent (Awange \& Kyalo Kiema, 2013; Melesse et al., 2007; Spitzer, 1986). Studies that have attempted to generate analytical insights and evidence have faced challenges, including the varying nature of co-benefits attributable to environmental initiatives, the typology and breadth of implementation approaches, and the data and methods used to assess co-benefits. The difference in methodology, data, and temporal and spatial scales also makes it tricky to draw overarching insights from these studies (Alpízar \& Ferraro, 2020; Naidoo et al., 2019).

Studies have begun applying satellite and other spatial data sources to assess the co-benefits of development initiatives. These studies have 

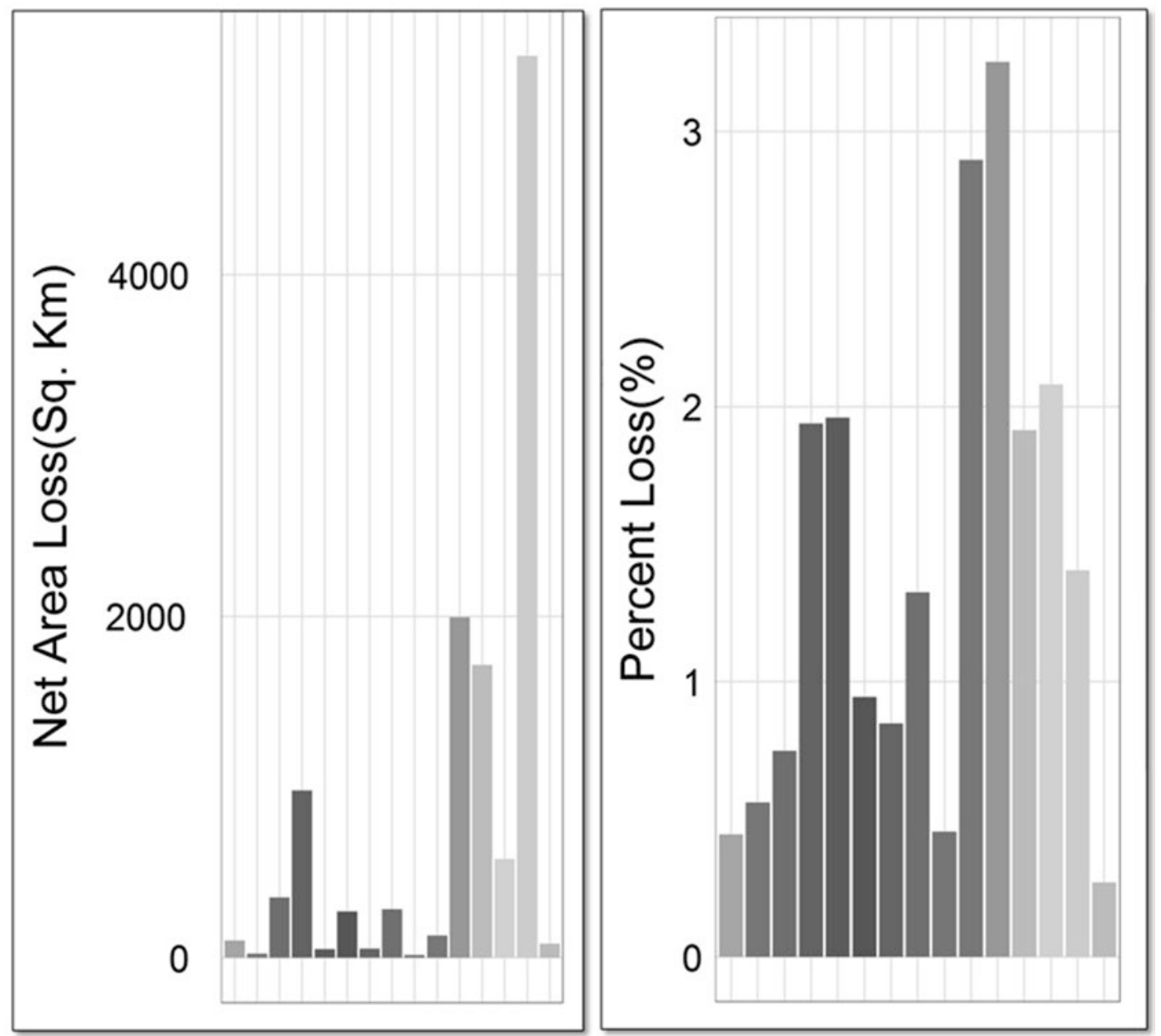

\section{Biome}

Boreal Forests/Taiga

Deserts \& Xeric Shrublands

Flooded Grasslands \& Savannas

Mangroves

Mediterranean Forests, Woodlands \& Scrub

Montane Grasslands \&' Shrublands

Others

Temperate Broadleaf \& Mixed Forests

Temperate Conifer Forests

Temperate Grasslands, Savannas \& Shrublands

Tropical \& Subtropical Coniferous Forests

Tropical \& Subtropical Dry Broadleaf Forests

Tropical \& Subtropical Grasslands, Savannas \& Shrublands

Tropical \& Subtropical Moist Broadleaf Forests

Tundra

Fig. 3 Levels of Loss in Protected Areas

demonstrated how to leverage satellite-based data sources for evaluating environmental outcomes. Building on the recent developments in research and impact evaluation, the GEF IEO conducted a study to estimate the global and local-level contributions of GEF environmental initiatives and their related benefits. 
IEO evaluators used a geospatial approach to determine the socioeconomic benefits associated with GEF-supported sustainable forest management (SFM) interventions. The GEF has a long history of providing support to improve the sustainability of forestry resources to increase environmental benefits and deliver socioeconomic co-benefits. This evaluation assessed the impacts of GEF-supported SFM interventions on biophysical and ecological variables and co-benefits measured in terms of socioeconomic indicators, and estimated monetary values of ecosystem services using the principle of natural capital accounting (Runfola et al., 2020). To examine the socioeconomic effects, the study used both a portfolio-wide approach (based on night light activity $^{3}$ ) and a recent case study from Uganda, which was the first attempt to combine geospatial data with other survey data. To detect the impact of GEF projects on proximate (within $50 \mathrm{~km}$ ) households, evaluators used the World Bank's Living Standards Measurement Survey of incountry household information (see Fig. 4).

The evaluation used the geographic locations of GEF SFM projects and data on the measurements of environmental outcomes based on suggested indicators from the CBD (2016) and UNCCD (2015). Night lights are a frequent proxy for socioeconomic outcomes, and the study used satellite-based measurements of nighttime light intensity over time. It also utilized a quasi-experimental approach to analyze GEF interventions' effectiveness along both environmental and socioeconomic dimensions. Details of this evaluation's methods and approaches are available in the original evaluation report (GEF IEO, 2019).

The portfolio-level, global scope analysis of economic and social co-benefits of GEF SFM projects indicated a small, positive impact on socioeconomic benefits as indicated by nighttime light intensity. The study found that projects implemented since 2010 showed a positive effect on nighttime lights $(+0.24)$, a proxy for economic

\footnotetext{
${ }^{3}$ Studies have demonstrated that nighttime light levels are highly correlated with economic activity, population, and establishment density (Mellander et al., 2015).
}

development, that had not been observed in prior years. The study noted that, in the absence of precise geographic location information, these findings could have been an underestimate of the actual impacts across the GEF SFM portfolio. The study recognized that results from the nighttime lights at the portfolio level were not evident and expanded the analysis to include local-level data. The local-scale case study in Uganda using survey data helped fill the portfolio-level analysis gap and further explore the impact of GEF SFM projects on socioeconomic outcomes. The results showed that GEF SFM projects were associated with an increase in household assets. By matching the longitudinal survey data locations from the World Bank household survey that were close to GEF interventions to those farther away from GEF intervention sites, the evaluation found that GEF SFM projects were associated with increased household assets between $\$ 163$ and \$353 (within 40-60 km, respectively). The Uganda case study showed that households proximate to a GEF implementation site tended to experience average improvements in assets of approximately $\$ 310$ (within $50 \mathrm{~km}$ ) as compared to those that were not close to a GEF implementation site. Although results from a single case study cannot be considered representative of the entire portfolio, the study provided useful insights that help in understanding the main dynamics taking place in these areas,

\section{Assessing Health Co-Benefits}

GEF-supported projects and programs seek to influence positive environmental outcomes across critical areas such as biodiversity, land degradation, and climate change by generating global and local environmental benefits. It is well understood that improved environmental outcomes such as cleaner air, water, and soil undisputedly contribute to better living conditions and health. The COVID-19 pandemic has compelled a reexamination of the consequences of environmental destruction and its direct implications for human health. Anthropogenic activities leading to land use mismanagement, 


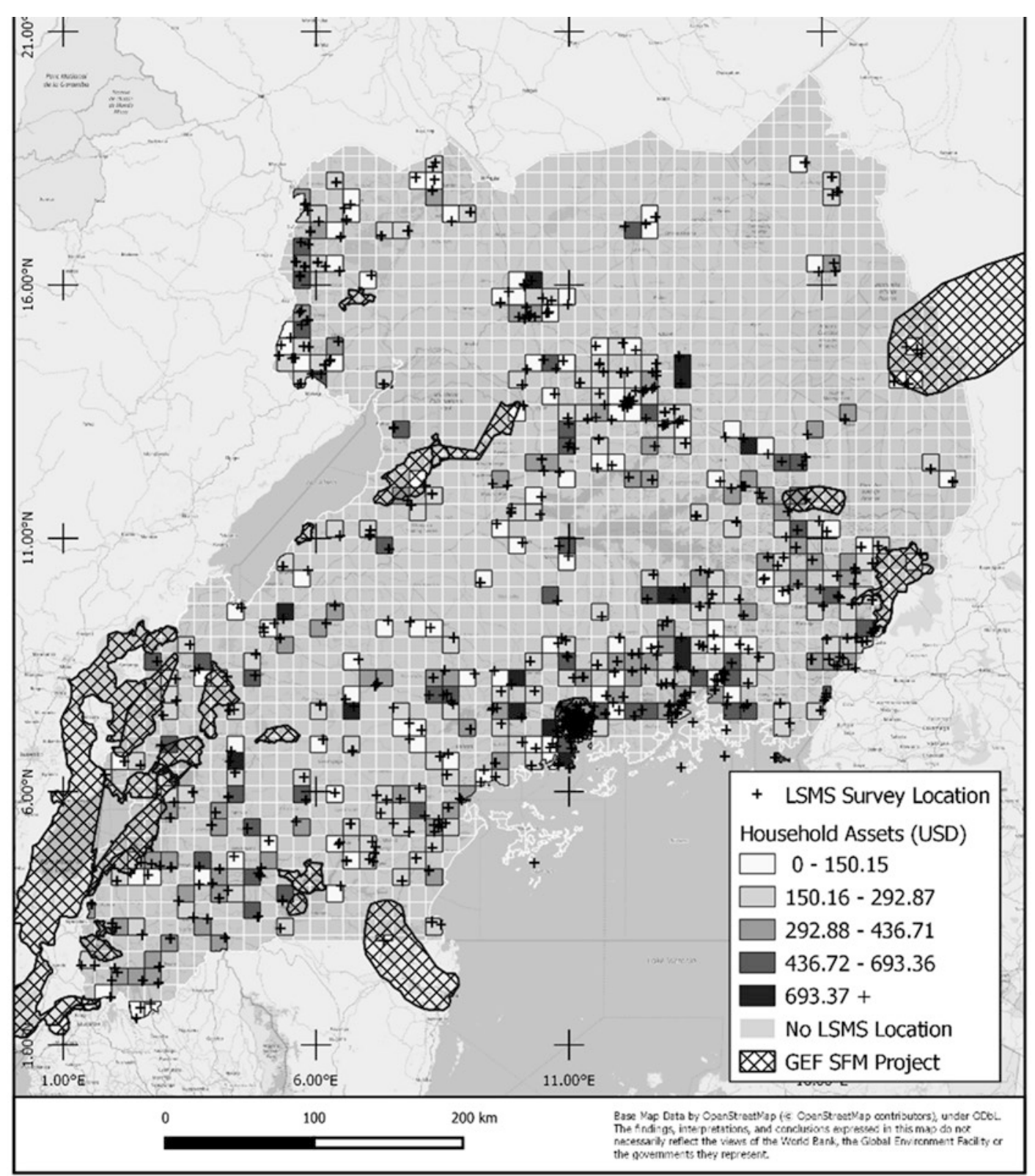

Fig. 4 GEF Project Impacts on Proximate Households Using World Bank's Living Standards Measurement Survey

fragmentation and destruction of natural habitats, and overexploitation of wildlife have fundamentally created more opportunities for the spread of infectious and zoonotic diseases (Liu et al., 2013; Olivero et al., 2020). Besides zoonotic diseases, poor water and air quality are still the leading causes of mortality worldwide. Therefore, human health issues cannot be sepa- rated from the environmental agenda and actions.

Building on the earlier work on SFM in Uganda, the GEF IEO undertook a further analysis to examine and quantify the association between GEF interventions and health cobenefits. The study looked at the health conditions of children under the age of 5 in Kenya, 
focusing on health measures including the prevalence of diarrhea and coughs (Fig. 5). The study explored whether improving environmental and socioeconomic co-benefits through GEFsupported projects led to improved health outcomes. It utilized the health survey dataset from the Kenya Department of Health Services (DHS, 2014), which contained 1594 survey clusters, each of which represented 19-25 households. The analyzed projects were drawn from the GEF's biodiversity, land degradation, climate change, and sustainable forest management focal areas and programs. Only projects implemented before 2014 were considered for the analysis. Evaluators used a quasi-experimental geospatial interpolation (QGI) method on Kenya's health data to quantify the association between GEF interventions and children's health conditions. The QGI method has three parameters: sample density, upper distance bound, and maximum matching difference. It uses a propensitymatching approach to pair treated and controlled survey clusters based on covariates. Runfola et al. (2020) provide more details on the QGI approach.

The study observed localized associations in both variables tested, with a $17 \%$ reduction in the occurrence of coughs within $10 \mathrm{~km}$ of the GEF intervention areas, and a $9 \%$ reduction in the occurrence of diarrhea within a distance of less than $3 \mathrm{~km}$. Besides these direct measures of health outcomes, GEF-supported projects also had positive impacts on water access, including the access to source water in dwellings and the presence of water at hand-washing facilities. The results were found to be stronger in clusters closer to GEF interventions (see Fig. 6).

\section{Assessing Outcome Sustainability in Fragile and Conflict Situations}

Assessing the sustainability of outcomes is challenging because, in most cases, projects do not have the resources or the mandate to look at the project results after closure. Examining outcome sustainability can be more of an issue in fragile and conflict-affected situations due to logistical and safety concerns. Geospatial analysis using remote sensing data can help in such situations where field visits and primary data collection are not possible.

The IEO used satellite-based data to assess the sustainability of environment-related project outcomes, part of the evaluation of GEF support in fragile and conflict-affected situations (GEF IEO, 2020). The IEO analysis looked at the trends in the change of forest cover in Sapo National Park, Liberia (Fig. 7). Evaluators compared the loss in forest cover for different periods (before, during, and after the project) to those periods in areas outside the protected areas and to trends in the overall national forest cover loss.

Sapo National Park is Liberia's only national park and a biodiversity hotspot within the Upper Guinea Forest ecosystem. It has faced longstanding threats from illegal farming, hunting, logging, and mining. In postwar Liberia, GEFsupported programming illustrates its catalytic potential in situations affected by conflict and fragility. The project Establishing the Basis for Biodiversity Conservation on Sapo National Park and in South-East Liberia, approved in 2004, marked one of the earliest GEF-funded projects in postwar Liberia. The World Bank implemented the project, and Flora and Fauna International (FFI) executed the project in collaboration with the Forestry Development Authority (FDA) of Liberia. The World Bank's re-engagement in Liberia started after the Second Liberian Civil War ended in 2003 (Independent Evaluation Group, World Bank [IEG], 2012, p. xiii.). Taking place from 2005-2010, the project was deemed successful, and project documents noted that "implementation occurred within a period of profound governance, environmental, institutional and societal changes in Liberia following a decade and half of the civil instability" (FFI, 2010, p i).

Since then, the GEF has supported various projects in Libera in different focal areas. Two other relevant GEF-funded projectsConsolidation of Liberia's Protected Area Network, from 2008 to 2012, and SPWA-BD: Biodiversity Conservation through Expanding the Protected Area Network in Liberia 

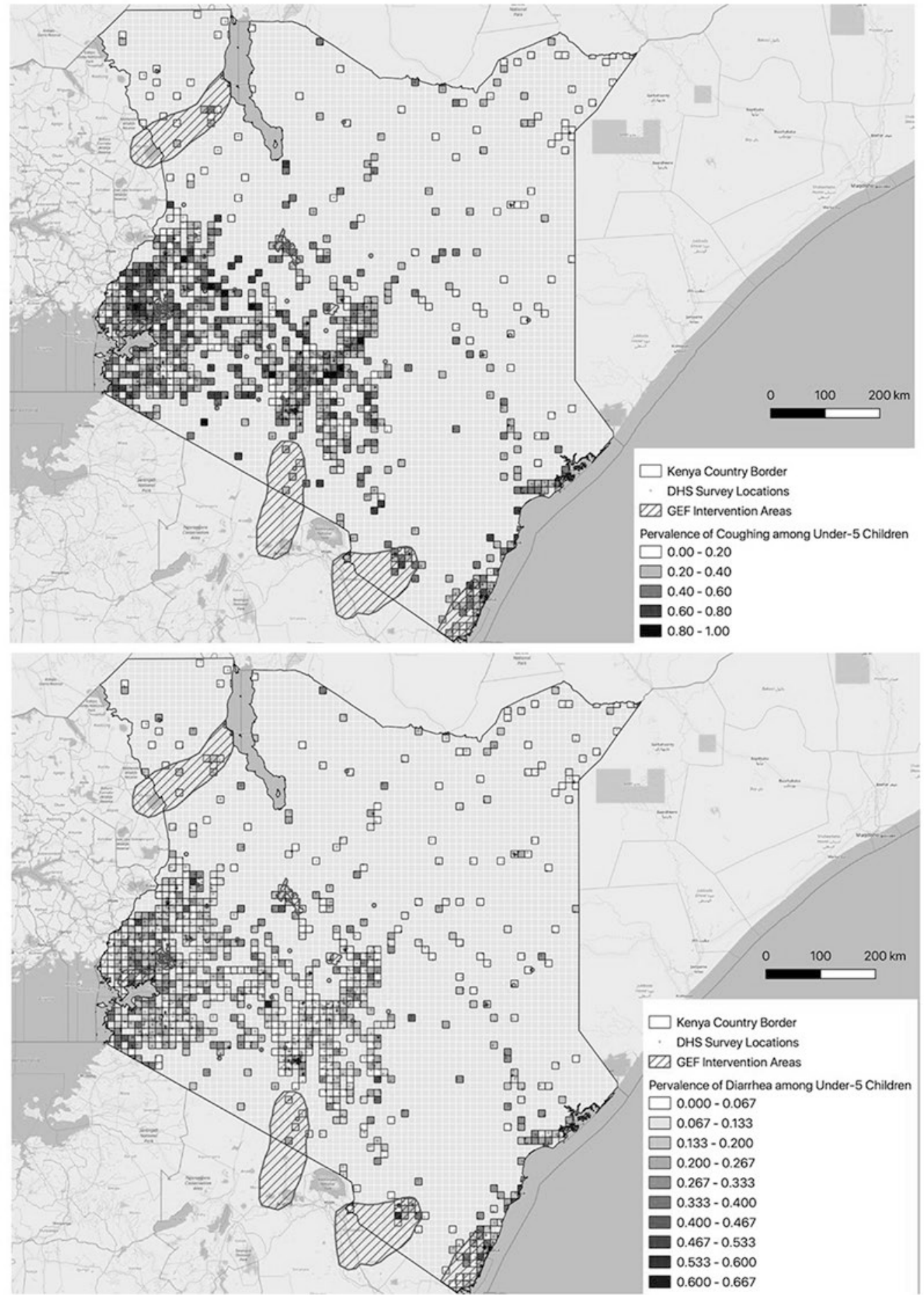

Fig. 5 Health Conditions of Children Under Age 5 in Kenya (Prevalence of Coughs and Diarrhea)

(EXPAN) - followed the first project and were also implemented by the World Bank. The Forest
Development Authority of Liberia executed the projects. Both of these projects were "built on 
Fig. 6 Health Co-Benefits of GEF-Supported Projects
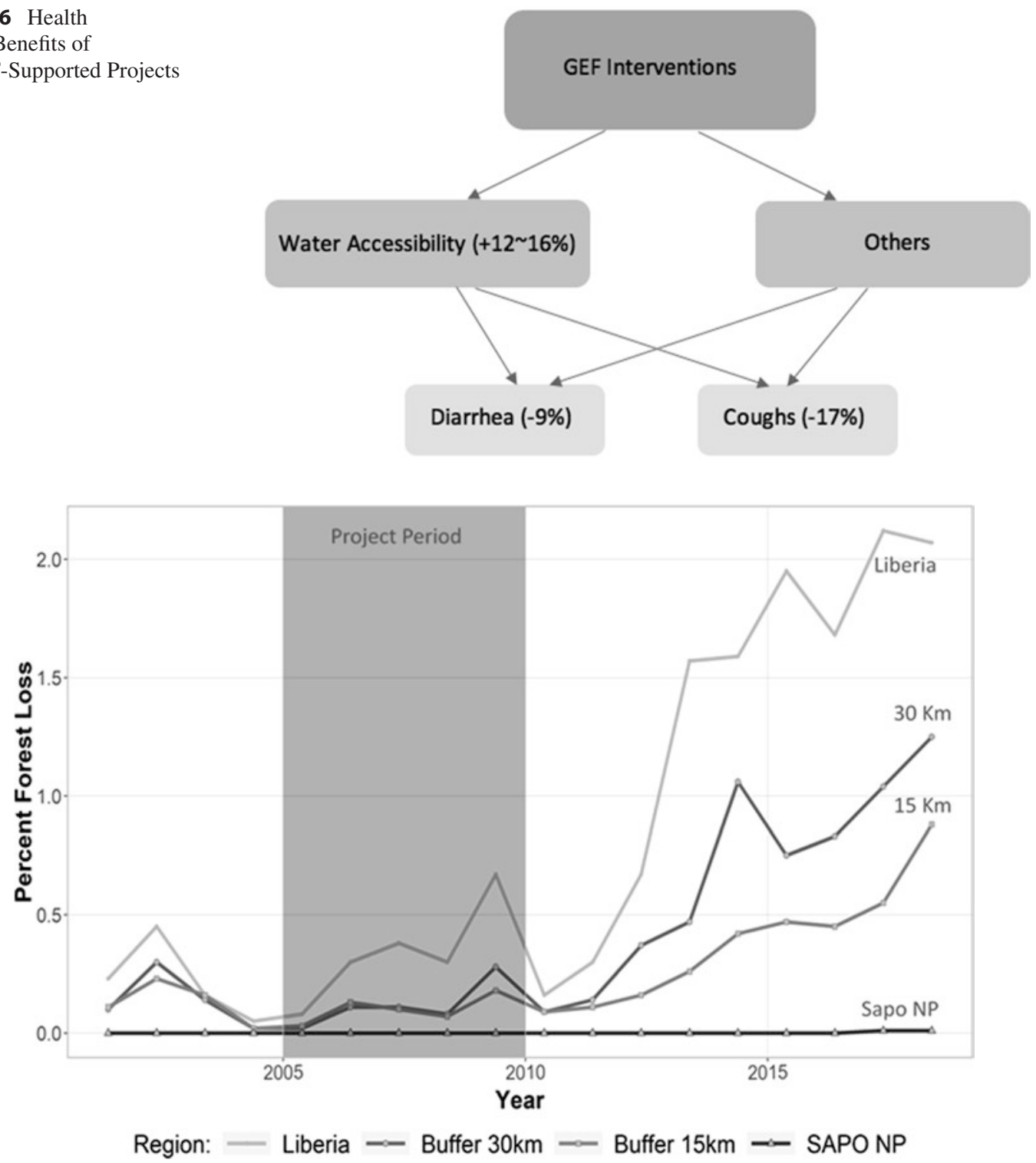

Fig. 7 Trends in Forest Cover in Sapo National Park, Liberia

successful GEF investments in Sapo NP" (World Bank, 2007, p. 4) and focused on biodiversity conservation, protected area management, community participation, and reducing rural dependence on forests and wildlife in Liberia.

Drawing on these projects' lessons, the World Bank continued its engagement with the forests and protected area interventions in Liberia, expanding the protected area systems and strengthening capacity to maintain them.
Ultimately, the Government of Liberia received grant funding (\$37.5 million) through the World Bank from the Government of Norway for the cost of the Liberia Forest Sector Project, 20162023, which expanded substantially on the initial GEF projects (World Bank, 2016). This project supports priority investments to strengthen the on-the-ground management of Sapo National Park, including physical demarcation, provision 
of vehicles and equipment, and updating the park's management plans (World Bank, 2016).

The remote sensing analysis results in Fig. 7 indicate minimal forest loss, close to zero deforestation within the park boundary (flat dark line). This could be explained by the prohibition on all economic activities, including mining, within national parks, as per Liberia's National Park legislation. Legal mining concessions are present in the buffer zone.

The results illustrate how efforts to protect Sapo National Park's resources during the first project have been sustained beyond the project duration and supported through subsequent interventions. This trend inside the park contrasts with the phenomenal increase in forest loss outside the park borders (see Fig. 8) and in Liberia as whole, mainly driven by illegal activities such as mining and logging for sustenance in the postwar nation.

The Liberian economy is highly dependent on natural resource exports from the mining, forestry, and rubber sectors. According to an International Monetary Fund (2008) study, the small-scale mining sector for gold and diamonds in the country was estimated to involve as many as 100,000 artisanal miners in 2008, but only 48 artisanal and small-scale mining (ASM) miners (Small \& Villegas 2012).

The two dips in the forest loss outside the Park (around 2005 and 2010) shown in Fig. 7 coincide with the eviction ${ }^{4}$ of illegal gold miners and settlers in Sapo National Park (FFI, 2010). The lack of financial, technical, and human resources, and lack of capacity and conducive legal environment in Liberia to effectively monitor ASM sites and other illegal activities also explain forest loss in the Sapo National Park's buffer zone (World Bank, 2020).

\section{Conclusions}

This chapter demonstrates the utility of geospatial approaches and data to evaluate complex environmental interventions and assess their

${ }^{4}$ The Liberian Government used the term "Voluntary departure" for the 2010-2011 removals. socioeconomic and health co-benefits. Geospatial analysis can help answer key evaluative questions on relevance, effectiveness, and sustainability of outcomes.

Geospatial methods can save financial and human resources and be very useful when working in hard-to-reach areas, especially in fragile and conflict situations or in a limiting context such as the COVID-19 pandemic. Geospatial analyses are also scalable and provide a costeffective and efficient approach for meaningful studies at the project site, portfolio level, and global level. The results generated through these methods provide objective evidence and thereby aid transparency. The analyses can also reveal patterns that are not obvious and help in understanding complex processes. Geospatial methods and approaches work well in a mixed-methods framework and assist with common evaluation challenges such as lack of baseline, finding the right counterfactuals, and addressing accessibility issues. The GEF IEO has used geospatial tools for sharing evaluation results through 2-D maps and interactive maps and visualizations. These tools facilitate the communication of complex ideas and information.

As environmental programming becomes complex as it interlinks with other economic and social variables, and the demand for globally consistent and locally relevant data keeps growing, geospatial data and analyses offer an efficient and complementary approach to evaluators to explore new and increasingly complex questions and topics. Whether applied on its own or in combination with other complementary data and processes, geospatial approaches and methods have undoubtedly opened up new avenues for use in evaluation, and are here to stay.

Acknowledgments The authors gratefully acknowledge the role of IEO partners with whom we have collaborated for these studies, including faculty at the University of Maryland, NASA, and AID DATA, who contributed to the various evaluations mentioned in this chapter. The material presented in the case studies is based on these completed evaluations. We particularly thank Min Feng, Dan Runfola, and Jiaying (Tina) Chen for their contributions. 
SAPO NP, Liberia - Forest Loss

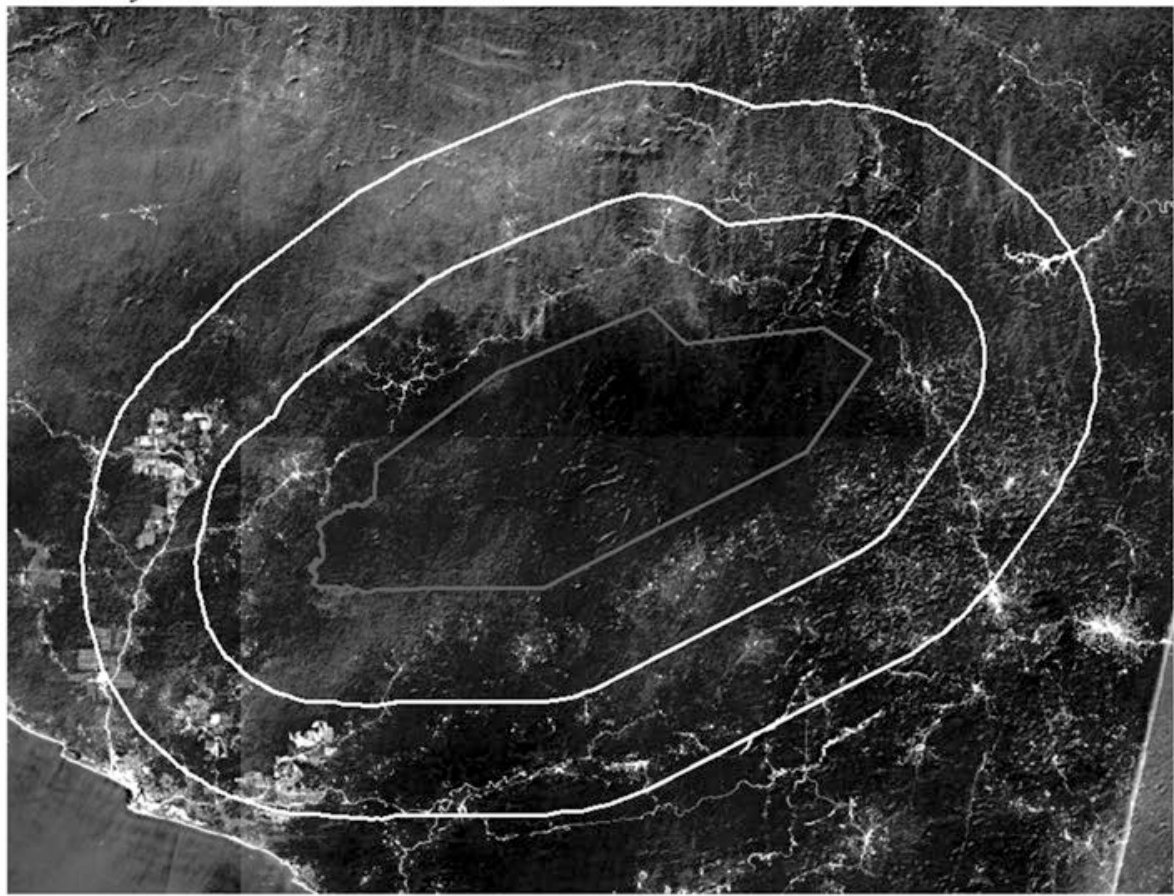

\section{SAPO NP, Liberia - Forest Loss}

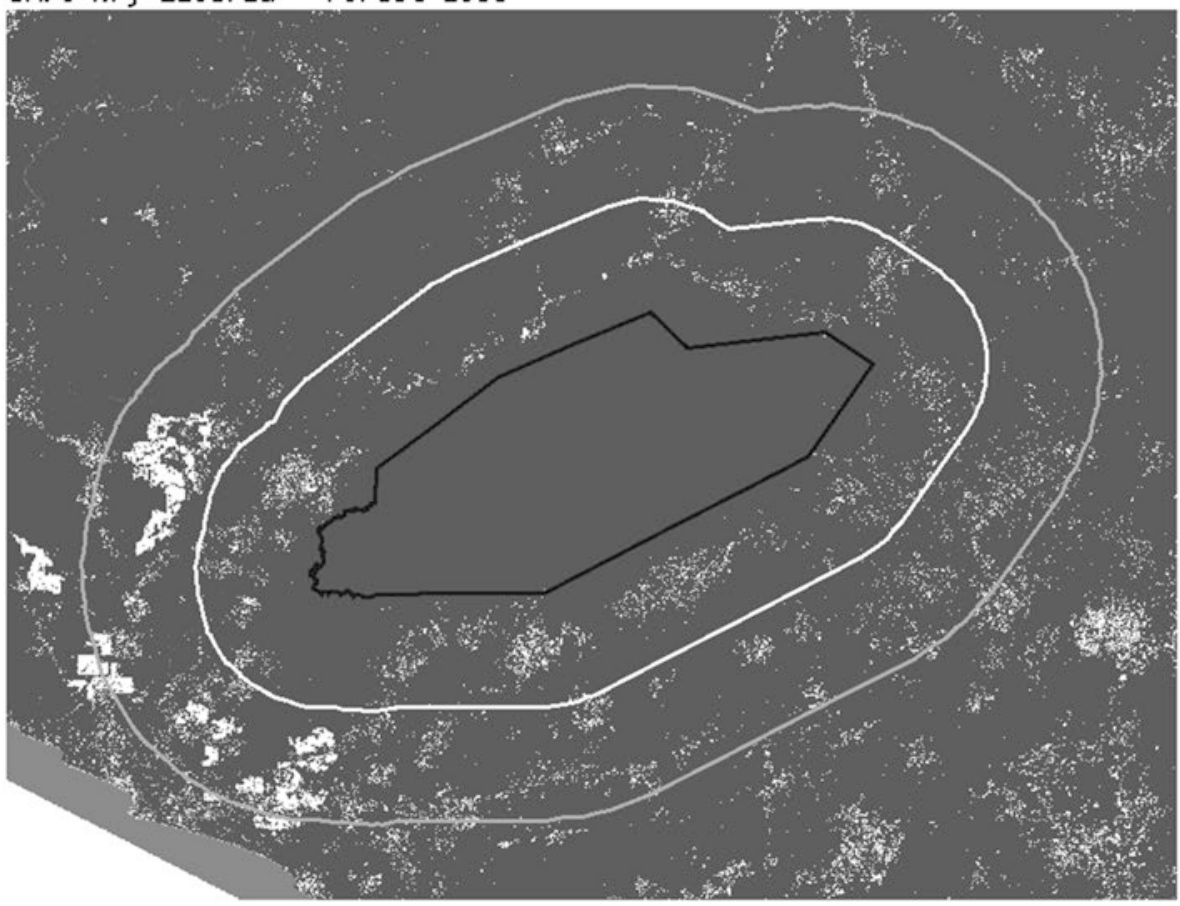

Fig. 8 Forest Loss Within and Outside of Sapo National Park, Liberia 


\section{References}

Alpízar, F., \& Ferraro, P. J. (2020). The environmental effects of poverty programs and the poverty effects of environmental programs: The missing RCTs. World Development, 127(March), 104783. https://doi. org/10.1016/j.worlddev.2019.104783.

Andam, K. S., Ferraro, P. J., Pfaff, A., Sanchez-Azofeifa, G. A., \& Robalino, J. A. (2008). Measuring the effectiveness of protected area networks in reducing deforestation. Proceedings of the National Academy of Sciences, 105(42), 16089-16094. https://doi. org/10.1073/pnas.0800437105.

Awange, J. L., \& Kyalo Kiema, J. B. (2013). Environmental monitoring and management. In J. L. Awange \& J. B. Kyalo Kiema (Eds.), Environmental geoinformatics: Monitoring and management (pp. 3-16). Berlin Heidelberg: Springer. https://doi. org/10.1007/978-3-642-34085-7_1.

Azzam, T. (2013). Mapping data, geographic information systems. New Directions for Evaluation, 2013(140), 69-84. https://doi.org/10.1002/ev.20074.

Azzam, T., \& Robinson, D. (2013). GIS in evaluation: Utilizing the power of geographic information systems to represent evaluation data. American Journal of Evaluation, 34(2), 207-224. https://doi. org/10.1177/1098214012461710.

Buchanan, G. M., Parks, B. C., Donald, P. F., O’Donnell, B. F., Runfola, D., Swaddle, J. P., Tracewski, Ł., \& Butchart, S. H. M. (2016). The impacts of World Bank development projects on sites of high biodiversity importance. College of William and Mary AidData. http://docs.aiddata.org/ad4/files/wps20_world_bank_ biodiversity.pdf

DeFries, R., Hansen, A., Newton, A. C., \& Hansen, M. C. (2005). Increasing isolation of protected areas in tropical forests over the past twenty years. Ecological Applications, 15(1), 19-26. https://doi. org/10.1890/03-5258.

Ferraro, P. J., \& Pattanayak, S. K. (2006). Money for nothing? A call for empirical evaluation of biodiversity conservation investments. PLoS Biology, 4(4), e105. https://doi.org/10.1371/journal.pbio.0040105.

Flora and Fauna International. (2010). Establishing the basis for biodiversity conservation on Sapo National Park and in south-east Liberia (Project implementation report). Author.

Global Environment Facility Independent Evaluation Office. (2016). Impact evaluation of GEF support to protected areas and protected area systems (Evaluation 104). https://www.gefieo.org/sites/default/files/ieo/ evaluations/files/BioImpactSupportPAs-2016.pdf

Global Environment Facility Independent Evaluation Office. (2017). Land degradation focal area study. https://www.gefieo.org/evaluations/ land-degradation-focal-area-ldfa-study-2017
Global Environment Facility Independent Evaluation Office. (2019). Value for money analysis of GEF interventions in support of sustainable forest management. https://www.gefieo.org/evaluations/value-moneyanalysis-gef-interventions-support-sustainable-forestmanagement-2019

Global Environment Facility Independent Evaluation Office. (2020). Evaluation of GEF engagement in fragile and conflict-affected situations. https://www. gefieo.org/evaluations/evaluation-gef-engagementfragile-and-conflict-affected-situations-2020

Hansen, M. C., Potapov, P. V., Moore, R., Hancher, M., Turubanova, S. A., Tyukavina, A., Thau, D., Stehman, S. V., Goetz, S. J., Loveland, T. R., Kommareddy, A., Egorov, A., Chini, L., Justice, C. O., \& Townshend, J. R. G. (2013). High-resolution global maps of 21stcentury forest cover change. Science, 342(6160), 850853. https://doi.org/10.1126/science.1244693.

Independent Evaluation Group, World Bank. (2012). Liberia country program evaluation: 2004-2011. https://ieg.worldbankgroup.org/sites/default/files/ Data/reports/Liberia_cpe.pdf

International Monetary Fund. (2008). Liberia: Poverty reduction strategy paper. IMF Staff Country Reports, 08(219), 1. https://doi. org/10.5089/9781451822984.002.

Jayachandran, S., de Laat, J., Lambin, E. F., Stanton, C. Y., Audy, R., \& Thomas, N. E. (2017). Cash for carbon: A randomized trial of payments for ecosystem services to reduce deforestation. Science, 357(6348), 267-273. https://doi.org/10.1126/science.aan0568.

Kass, G. (2019). Systems approaches for tackling environmental issues. Institution of Environmental Sciences. https://www.the-ies.org/analysis/ systems-approaches-tackling

Kenya Department of Human Services. (2014). Kenya demographic and health survey 2014. https://dhsprogram.com/publications/publication-fr308-dhs-finalreports.cfm

Lech, M., Uitto, J. I., Harten, S., Batra, G., \& Anand, A. (2018). Improving international development evaluation through geospatial data and analysis. International Journal of Geospatial and Environmental Research, 5(2) https://dc.uwm.edu/ijger/vol5/iss2/3.

Liu, X., Rohr, J. R., \& Li, Y. (2013). Climate, vegetation, introduced hosts and trade shape a global wildlife pandemic. Proceedings of the Royal Society B: Biological Sciences, 280(1753), 20122506. https:// doi.org/10.1098/rspb.2012.2506.

Melesse, A. M., Weng, Q., Thenkabail, P. S., \& Senay, G. B. (2007). Remote sensing sensors and applications in environmental resources mapping and modelling. Sensors, 7(12), 3209-3241.

Mellander, C., Lobo, J., Stolarick, K., \& Matheson, Z. (2015). Night-time light data: A good proxy measure for economic activity? PLoS One, 10(10), e0139779. https://doi.org/10.1371/journal.pone.0139779. 
Minelli, S., Erlewein, A., \& Castillo, V. (2017). Land degradation neutrality and the UNCCD: From political vision to measurable targets. In H. Ginzky, I. Heuser, T. Qin, O. Ruppel, \& P. Wegerdt (Eds.), International yearbook of soil law and policy 2016 (pp. 85-104). Springer. https://doi. org/10.1007/978-3-319-42508-5_9.

Naidoo, R., Gerkey, D., Hole, D., Pfaff, A., Ellis, A. M., Golden, C. D., Herrera, D., Johnson, K., Mulligan, M., Ricketts, T. H., \& Fisher, B. (2019). Evaluating the impacts of protected areas on human well-being across the developing world. Science Advances, 5(4), eaav3006. https://doi.org/10.1126/sciadv.aav3006.

Olivero, J., Fa, J. E., Farfán, M. A., Márquez, A. L., Real, R., Juste, F. J., Leendertz, S. A., \& Nasi, R. (2020). Human activities link fruit bat presence to ebola virus disease outbreaks. Mammal Review, 50(1), 1-10. https://doi.org/10.1111/mam.12173.

Renger, R., Cimetta, A., Pettygrove, S., \& Rogan, S. (2002). Geographic information systems (GIS) as an evaluation tool. American Journal of Evaluation, 23(4), 469479. https://doi.org/10.1177/109821400202300407.

Runfola, D., Batra, G., Anand, A., Way, A., \& Goodman, S. (2020). Exploring the socioeconomic co-benefits of Global Environment Facility projects in Uganda using a quasi-experimental geospatial interpolation (QGI) approach. Sustainability, 11(18), 3225. https://doi. org/10.3390/su12083225.

Small, R., \& Villegas, C. (2012). Artisanal and smallscale mining in and around protected areas and critical ecosystems project: Liberia case study report.
WWF-World Wide Fund for Nature and Estelle Levin. https://www.levinsources.com/assets/pages/ASMLiberia-Final.pdf

Spitzer, D. (1986). On applications of remote sensing for environmental monitoring. Environmental Monitoring and Assessment, 7(3), 263-271. https:// doi.org/10.1007/BF00418019.

United Nations Environment Programme. (2002). Global environment outlook 3: Past, present and future perspectives. Earthscan.

United Nations Environment Programme. (2013). Embedding the environment in sustainable development goals (UNEP Post-2015 Discussion Paper 1 Version 2). https://sustainabledevelopment.un.org/ content/documents/972embedding-environments-inSDGs-v2.pdf

World Bank. (2007). Consolidation of Liberia's protected area network implementation completion memorandum (ICM). https://www.thegef.org/project/ consolidation-liberias-protected-area-network

World Bank. (2016). Liberia - Forest sector project, project appraisal document. http://documents1. worldbank.org/curated/en/385131468184765418/pdf/ PAD1492-PAD-P154114-Box394888B-PUBLICLFSP-PAD-FINAL.pdf

World Bank. (2020). Liberia Forestry Development Authority: An institutional capacity assessment. https://www.profor.info/sites/profor.info/files/LiberiaForestry-Development-Authority-An-InstitutionalCapacity-Assessment.pdf

Open Access This chapter is licensed under the terms of the Creative Commons Attribution 4.0 International License (http://creativecommons.org/licenses/by/4.0/), which permits use, sharing, adaptation, distribution and reproduction in any medium or format, as long as you give appropriate credit to the original author(s) and the source, provide a link to the Creative Commons license and indicate if changes were made.

The images or other third party material in this chapter are included in the chapter's Creative Commons license, unless indicated otherwise in a credit line to the material. If material is not included in the chapter's Creative Commons license and your intended use is not permitted by statutory regulation or exceeds the permitted use, you will need to obtain permission directly from the copyright holder. 